\title{
Energy expenditure associated with walking speed and angle of turn in children
}

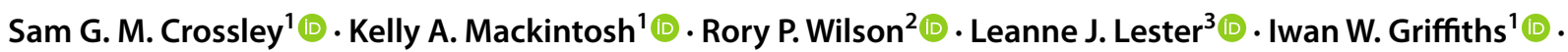 \\ Melitta A. McNarry ${ }^{1}$ D
}

Received: 26 February 2018 / Accepted: 18 August 2018 / Published online: 5 September 2018

(c) The Author(s) 2018

\begin{abstract}
Purpose Recent studies have suggested that turning is power intensive. Given the sporadic and irregular movement patterns of children, such findings have important implications for the assessment of true energy expenditure associated with habitual physical activity. The purpose of this study was to investigate the influence of walking speed and angle, and their interaction, on the energy expenditure of healthy children.

Methods 20 children ( $10.1 \pm 0.5$ years; 10 boys) participated in the study. On two separate days, participants completed a turning protocol involving 3-min bouts of walking at one of the 16 speed $\left(2.5,3.5,4.5\right.$, and $\left.5.5 \mathrm{~km} \mathrm{~h}^{-1}\right)$ and angle $\left(0^{\circ}, 45^{\circ}\right.$, $90^{\circ}$, and $180^{\circ}$ ) combinations, interspersed by $3 \mathrm{~min}$ seated rest. The movement involved $5 \mathrm{~m}$ straight walking interspaced with prescribed turns with speed dictated by a digital, auditory metronome. Breath-by-breath gas exchange was measured, in addition to tri-axial acceleration and magnetic field intensity recorded at $100 \mathrm{~Hz}$.

Results Mixed models revealed a significant main effect for speed $(p<0.006)$ and angle $(p<0.006)$, with no significant interaction between speed and angle $(p>0.006)$. Significant differences to straight-line walking energy expenditure within speed were established for 3.5 and $5.5 \mathrm{~km} \mathrm{~h}^{-1}$ for $180^{\circ}$ turns ( $\sim 13 \%$ and $\sim 30 \%$ increase, respectively).

Conclusion These findings highlight the importance of accounting for the magnitude and frequency of turns completed when estimating children's habitual physical activity and have significant implications for the assessment of daily energy expenditure.
\end{abstract}

Keywords Youth $\cdot$ Energy requirements $\cdot$ Velocity $\cdot$ Change of direction

$\begin{array}{ll}\text { Abbreviations } \\ \text { BMI } & \text { Body mass index } \\ \text { DBA } & \text { Dynamic body acceleration } \\ \text { GET } & \text { Gas exchange threshold } \\ \text { PHV } & \text { Peak height velocity } \\ \text { VeDBA } & \text { Vectorial dynamic body acceleration } \\ C_{\mathrm{r}} & \text { The net energy cost of walking }\end{array}$

Communicated by Jean-René Lacour.

Sam G. M. Crossley

S.G.M.Crossley@swansea.ac.uk

1 Applied Sport Technology Exercise and Medicine Research Centre, Swansea University, Swansea, Wales, UK

2 Swansea Lab for Animal Movement, Biosciences, College of Science, Swansea University, Singleton Park, Swansea, Wales, UK

3 School of Human Science, The University of Western Australia, Crawley, Australia
$\dot{V} \mathrm{O}_{2} \quad$ Oxygen uptake

$\dot{V} \mathrm{O}_{2 \text { peak }}$ Peak oxygen uptake

6MWT Six-minute walking test

TCH Tukey-Ciminera-Heyse

\section{Introduction}

Insufficient physical activity is one of the leading risk factors for global mortality, at least in part due to its association with obesity and non-communicable diseases (NCDs), such as cardiovascular disease, cancer, and diabetes (WHO 2017). However, despite the numerous physiological (Janssen and Leblanc 2010; Sothern et al. 1999) and psychosocial benefits (Eime et al. 2013; Nieman 2002) associated with physical activity, it is suggested that as little as $19 \%$ of boys and $16 \%$ of girls meet the current government guidelines of $60 \mathrm{~min}$ of moderate-to-vigorous physical activity every day (Townsend 
et al. 2015). A central tenet to these guidelines is the link between defined physical activity and energy expenditure.

The most accurate measure of an individual's physical activity and energy expenditure is by assessing the body's oxygen utilization and carbon dioxide production using indirect calorimetry methods (Levine 2005). However, this level of measurement is expensive and in-practical in free-living settings (Strath et al. 2013; Westerterp 2009), although does provide an essential criterion method by which to judge the accuracy and precision of smaller and less obtrusive devices such as accelerometers (Freedson et al. 2005; Rowlands 2007). Accelerometers have been widely utilized among researchers (Doherty et al. 2017; Lee and Shiroma 2014; Leung et al. 2017; Ward et al. 2005) as a result of their relatively accurate estimates of oxygen uptake $\left(\dot{V} \mathrm{O}_{2}\right.$; de Almeida Mendes et al. 2018; McGregor et al. 2009). Nevertheless, there are some limitations to accelerometer measurements as they are most commonly based upon linear regression models that emphasize that energy expenditure increases linearly with vertical accelerations (Freedson et al. 2012), which tend to discredit non-locomotive activities, such as turning (Bassett and John 2010; Chen et al. 2007; Van Remoortel et al. 2012). In this regard, children are problematic, since their movement is highly sporadic (Baquet et al. 2007; Sleap and Warburton 1996; Welk et al. 2000), which presents challenges to power-use determination protocols that typically require steady-state conditions (Reilly et al. 2004; Trost et al. 2011). Subsequently, the development of new multi-sensor devices that integrate both accelerometer and magnetometer measurements have been extensively used as a proxy of $\dot{V} \mathrm{O}_{2}$ in humans (McNarry et al. 2017; Qasem et al. 2012; Weippert et al. 2013) as a result of the combined ability to capture additional information regarding how the body rotates during pathways that require turning (Williams et al. 2017) .

Turning is a fundamental movement within human locomotion and is particularly prevalent in children's habitual physical activity patterns (Sleap and Warburton 1996). Even within adults, turning can make up $35-45 \%$ of all steps taken in a typical day (Glaister et al. 2007). While turning has not generally been considered to be associated with significant additional energetic costs over straight-line walking, this attitude is now changing (Dellal et al. 2010). According to Hamill et al. (1983), curved path locomotion or turning may subject individuals to unique stresses. For example, a study in 2011 suggested that $15 \%$ of the total energy expenditure during stair climbing can be attributed to turning in adults (Minetti et al. 2011), while Buchheit et al. (2011) reported marked physiological changes associated with turning; increased heart rate, blood lactate, and perceived exertion during intermittent shuttle run tests with a $180^{\circ}$ turn compared to straight running. Similarly, it has been shown that completing 30 turns per minute at $3 \mathrm{~km} \mathrm{~h}^{-1}$ elicits a similar energy expenditure to straight-line walking at $6 \mathrm{~km} \mathrm{~h}^{-1}$ (Hatamoto et al. 2014). Furthermore, Wilson et al. (2013) extended these findings to consider a range of turning angles, demonstrating that as the angle of the turn increased, so did the associated energy expenditure. Specifically, a single $180^{\circ}$ turn elicited the same energy expenditure as walking $5.88 \mathrm{~m}$ in a straight line at a velocity of $1.67 \mathrm{~m} \mathrm{~s}^{-1}\left(6 \mathrm{~km} \mathrm{~h}^{-1}\right)$. To consider these findings as a function of walking speed, McNarry et al. (2017) reported a synergistic interaction between speed and angle in determining the energy expenditure associated with walking. A similar study investigated the energy expenditure of turning and walking in community-dwelling elderly, reporting that $180^{\circ}$ turns were significantly more energy demanding than $90^{\circ}$ turns (Justine et al. 2014). However, the applicability of these findings to children is questionable, not least due to their unique physiological and biomechanical structure (Andropoulos 2012). To date, no studies have specifically addressed the energy expenditure of turning in children. Such findings will have important implications for developing technology that enables a more precise unobtrusive assessment of children's physical activity and intensity that is essential for detailed investigations of dose-response relationships between physical activity and health, the evaluation of interventions and enhancing an individual's awareness of their physical state to enforce behaviour change.

The purpose of the present study was to investigate the influence of turn angle and walking speed on energy expenditure in children. We hypothesized that (1) as speed of walking increased, so too would the energy expenditure; (2) as angle of turn increased, so would the energy expenditure and that (3) walking speed and angle of turn would interact to modulate energy expenditure.

\section{Methods}

\section{Participants and anthropometry}

Twenty healthy children, aged $9-12$ years $(10.1 \pm 0.5$ years; 10 boys) were recruited from a local primary school. Child assent and parental or guardian consent were obtained prior to study participation. Body mass (Seca 876, Hamberg, Germany), stature (Holtain Stadiometer, Holtain Ltd), and sitting height (Holtain Sitting Height Stadiometer, Holtain Ltd) were measured to the nearest $0.1 \mathrm{~kg}$ and $0.1 \mathrm{~cm}$, respectively. Sexual maturity was assessed by self-report using the indices of pubic hair described by Tanner (1962). Pre-pubertal status was defined as Tanner stage $1(n=12)$, with stage 2 being early pubertal $(n=4)$, Tanner stage 3 mid-pubertal $(n=4)$, Tanner stages 4 and 5 being late pubertal, and post pubertal, respectively (Chan et al. 2010). To provide an additional indicator of physical maturity, the age to peak height velocity equation devised by Mirwald et al. (2002) was used based 
on the measurement of standing and seated height, weight, and age to calculate maturity offset. Participants were asked to arrive at the laboratory in a rested state, at least 2-h postprandial. All procedures employed during this study were approved by Swansea University ethics committee and were conducted in accordance with the Declaration of Helsinki (ref: PG/2014/16).

\section{Incremental treadmill test}

Participants were required to visit the laboratory on one occasion to perform an incremental treadmill test to volitional exhaustion for the determination of the gas exchange threshold (GET) and peak oxygen uptake $\left(\dot{V} \mathrm{O}_{2 \text { peak }}\right)$. The children were first familiarised with walking and running on the treadmill at a range of speeds $\left(4,6\right.$, and $\left.8 \mathrm{~km} \mathrm{~h}^{-1}\right)$ and with the testing equipment. To take into account the variation in biological ages, individual $\dot{V} \mathrm{O}_{2 \text { peak }}$ test speeds were calibrated by anchoring treadmill speeds to set Froude numbers (Houston et al. 2013). Specifically, treadmill speeds were calculated using the Froude number, gravity, and leg length equation (Minetti 2001). The initial stages were set at a $1 \%$ gradient (Jones and Doust 1996) and increased every 2 min, beginning with a walking speed equivalent to Froude 0.25 . Subsequent increments were determined by the calculated difference between stage 1 and 2 speeds $\left(\sim 2 \mathrm{~km} \mathrm{~h}^{-1}\right)$ until maximal running velocity was achieved. At this point, the gradient was then increased by $1 \%$ every minute until volitional exhaustion was reached.

\section{Turning protocol}

The second part of the testing involved completing a turning protocol, which was repeated on two occasions, separated by a minimum of $24 \mathrm{~h}$. During this protocol, each participant was asked to complete 3-min bouts of walking interspersed by 3 min of seated rest. Each participant walked at four different walking speeds $\left(2.5,3.5,4.5\right.$, and $\left.5.5 \mathrm{~km} \mathrm{~h}^{-1}\right)$ in combination with four different turn angles $\left(0^{\circ}, 45^{\circ}, 90^{\circ}\right.$, and $180^{\circ}$ ), in a randomized order, as illustrated in Fig. 1. Specifically, each of the conditions involved $5 \mathrm{~m}$ straight walking stretches interspaced with prescribed turns with the speed dictated by a digital, auditory metronome. The auditory metronome sounded half-way along the $5 \mathrm{~m}$ straight and on the turns, so variability in speed within conditions was minimised. Furthermore, all participants were accompanied by one of the research team to act as a pacesetter. Each condition incorporated an equal number of left and right turns.

\section{Measurements}

Throughout all the tests, gas exchange variables were measured on a breath-by-breath basis (MetaMax Cortex 3B, CORTEX Biophysik GmbH, Germany). Prior to each test, the gas analysers were calibrated using gases of known concentration and the turbine volume transducer was calibrated using a 3-L syringe (Hans Rudolph, Kansas City, MO, USA). The delay in the capillary gas transit and analyser rise time was accounted for relative to the volume signal, thereby time-aligning the concentration and volume signals. In addition, two custom-built tri-axial accelerometers and magnetometers (SLAM Tracker, Wildbyte Technologies Ltd, Swansea, UK), measuring at $100 \mathrm{~Hz}$ on all channels, were worn by participants: one tag was worn on the right mid-axilla line at the level of the iliac crest and one tag at the middle of the lower back (see Fig. 2), in accord with the previous methods (McNarry et al. 2017).
Fig. 1 Experimental setup of the turning protocol showing $5 \mathrm{~m}$ straights interspersed by prescribed angle of turns $\mathbf{a} 0^{\circ}$, b $45^{\circ}$, c $90^{\circ}$, and d $180^{\circ}$ with equal left and right hands turns a

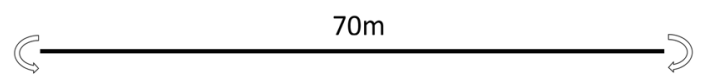

b

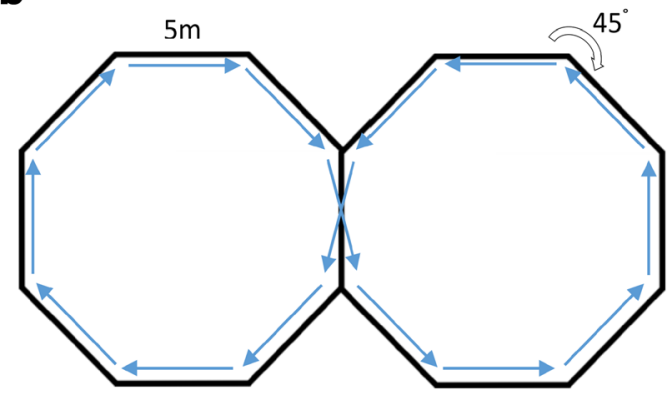

C

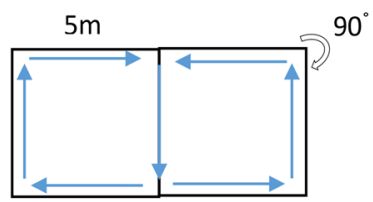

d 
Fig. 2 SLAM tracker device placement: a right mid-axilla line at the level of the iliac crest; $\mathbf{b}$ middle of the lower back
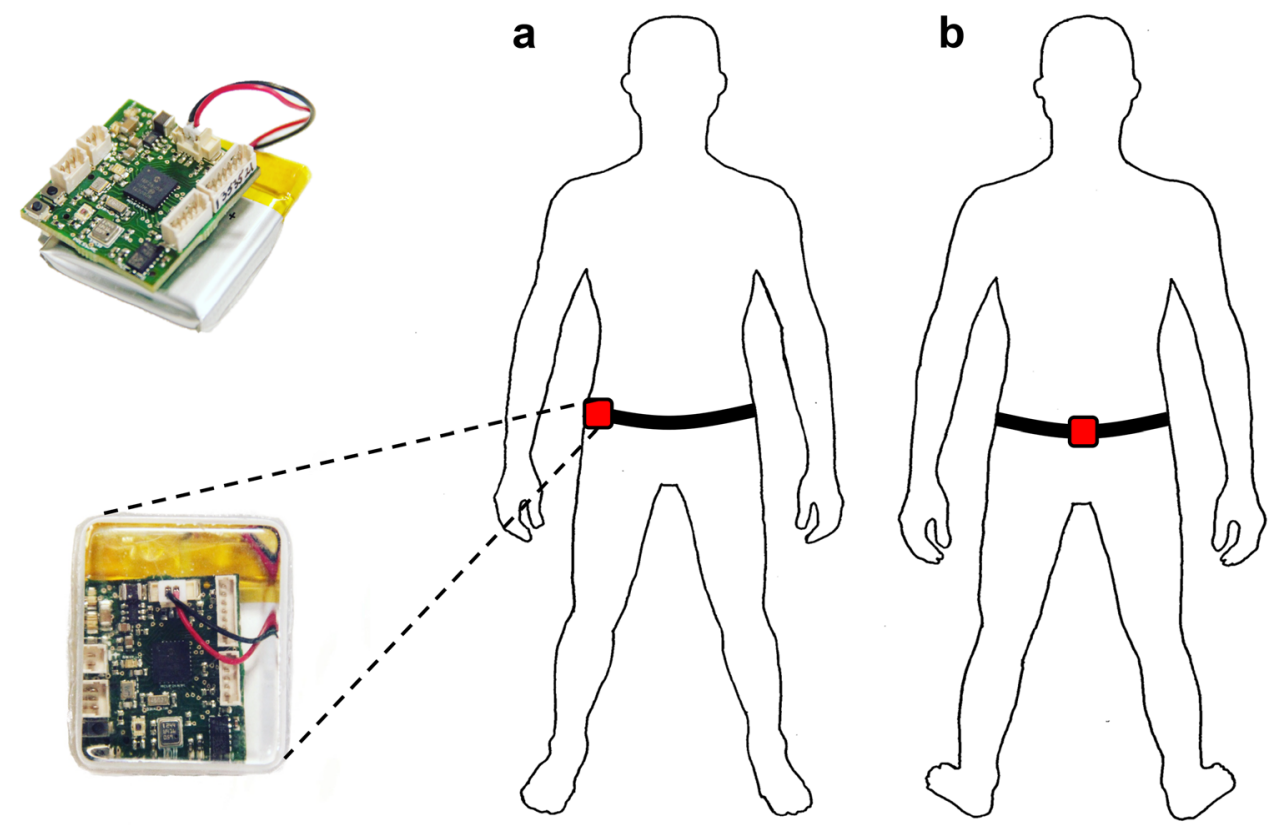

\section{Data analysis}

$\dot{V} \mathrm{O}_{2 \text { peak }}$ was defined as the highest 10 -s stationary average during the incremental exercise test. The GET was determined by the $V$-slope method (Beaver et al. 1986) as the point at which carbon dioxide production began to increase disproportionately to $\dot{V} \mathrm{O}_{2}$, as identified using the purposewritten software developed using LabVIEW (National Instruments, Newbury, UK). Mean absolute $\dot{V} \mathrm{O}_{2}$ values for defining steady state for each individual speed and turn were taken from the last $45 \mathrm{~s}$ of each 3-min turning condition (Wilson et al. 2013). Analyses of turning energy expenditure were based on the premise that the additional turn cost was superimposed on the baseline of straight-line travel. Specifically, the difference in $\dot{V} \mathrm{O}_{2}$ between straight-line walking $\left(0^{\circ}\right)$ at each velocity relative to the $\dot{V} \mathrm{O}_{2}$ associated with walking at $45^{\circ}, 90^{\circ}$, or $180^{\circ}$ turns was defined as the additional cost of turning. The net energy cost of walking $\left(C_{\mathrm{r}}\right)$ was calculated from participants' absolute $\dot{V} \mathrm{O}_{2}$ values normalized per unit body mass for each experimental condition and divided by the walking speed converted to meters per minute $(\mathrm{m} / \mathrm{min})$, expressed as $\mathrm{ml} \mathrm{O}_{2} \cdot \mathrm{kg}^{-1} \mathrm{~km}^{-1}$. To account for body size, the procedures proposed by Welsman and Armstrong (2000) were used to calculate the allometric scaling coefficient for absolute $\dot{V} \mathrm{O}_{2}$ for turning, straights, and $\dot{V} \mathrm{O}_{2 \text { peak }}$. First, the data were logarithmically transformed to determine the allometric relationship between body mass, $\dot{V} \mathrm{O}_{2}$ and $\dot{V} \mathrm{O}_{2 \text { peak }}$. Common allometric exponents were confirmed, which were then linearly regressed to obtain a coefficient and then expressed using the formula:

Scaled $\dot{V} \mathrm{O}_{2}=Y / X^{b}$, where $Y$ is the participants $\dot{V} \mathrm{O}_{2}$ for a turn, straight or $\dot{V} \mathrm{O}_{2 \text { peak }}, X$ is the body mass of the participant, and $b$ is the scaling coefficient derived from the linear regression.

Significant absolute and scaled $\dot{V} \mathrm{O}_{2}$ outliers were established using box plots with Tukeys 1.5 multiplier of the standard deviation (Tukey 1977). Subsequently, one participant was excluded from further analyses due to significant outliers identified in test 1 .

The raw accelerometer data were first converted to dynamic body acceleration (DBA) by smoothing each channel to derive the static acceleration using a running mean over $2 \mathrm{~s}$ (Shepard et al. 2008). The static acceleration was then subtracted from the raw acceleration data (Gleiss et al. 2011), resulting in values for dynamic acceleration that were all converted to positive values. These values for DBA were summed vectorially to provide 'vectorial dynamic body acceleration' (VeDBA):

$\operatorname{VeDBA}=\sqrt{\left(A_{x}^{2}+A_{y}^{2}+A_{z}^{2}\right)}$,

where $A_{x}, A_{y}$, and $A_{z}$ are the derived dynamic accelerations at any point in time corresponding to the three orthogonal axes of the accelerometer (Qasem et al. 2012). VeDBA has been used extensively as a proxy for $\dot{V} \mathrm{O}_{2}$ in a suite of vertebrates (cf. Halsey et al. 2011), including humans (McNarry et al. 2017; Qasem et al. 2012; Weippert et al. 2013), with appreciable success. However, many aspects of the particulars of the acceleration data recorded in such trials (e.g., lateral versus forward-backward) as well as the effect of incline (cf. Bidder et al. 2012) and tag mounting have not been examined critically, so our use of this metric has to be seen within this context. 
Using the middle minute and overall 3-min bout, both mean and summed VeDBA were derived for each individual turn and straight for each condition. The individual turns and straight sections were analyzed using a custom developed C++ software (DDMT Wildbyte Technologies Ltd, Swansea, UK) specially designed for visualizing the accelerometry and magnetometry traces to identify inter alia turns via systematic changes in the magnetometry data (Williams et al. 2017).

\section{Statistics}

A Sharpiro-Wilks test was used to confirm data normality. Repeated measures linear mixed-effects models with a Tukey's test of post hoc means test were conducted using IBM SPSS Statistics 22 (Chicago, IL, USA) to account for the repeated measures and correlated nature of the data to determine the influence of, and interaction between, independent variables walking speed and angle, with the dependent variables expressed as $C_{\mathrm{r}}$, absolute $\dot{V} \mathrm{O}_{2}$, scaled $\dot{V} \mathrm{O}_{2}$, and mean VeDBA (Halsey et al. 2009; Qasem et al. 2012). All condition combinations for turning $\dot{V} \mathrm{O}_{2}$ (absolute or scaled) and mean VeDBA (straight or turn) were placed into one mixed model analysis with covariates (sex, stature, and cardiorespiratory fitness) to determine their modulatory effect. The Tukey-Ciminera-Heyse (TCH; Sankoh et al. 1997; Tukey et al. 1985) procedure was used to determine an adjusted significance value for all comparisons within the mixed model to account for experimentwise error. A Pearson product-moment correlation coefficient was used to determine any associations between the dependent variables $\dot{V} \mathrm{O}_{2}$ and straight and turn VeDBA, including all covariates. All data are presented as mean \pm SD.

\section{Results}

The characteristics of the sample population are displayed in Table 1. Boys were significantly heavier, taller and demonstrated a higher peak $\dot{V} \mathrm{O}_{2}$ than girls, in both absolute and scaled terms. All participants were found to be either pre-pubertal or early-to-mid-pubertal according to the self-reported Tanner stages. To determine the relationship between walking speed and angle on energy expenditure, a mixed model was used to examine the main effects of speed and angle, and the interaction of speed and angle while controlling for sex. Our post hoc evaluations indicated that the empirical technique utilized fully met the intended objectives. The $\mathrm{TCH}$ procedure resulted in an adjusted significance value of $0.006(6)$, calculated from 60 pairwise comparisons.

The values of $C_{\mathrm{r}}$, for all participants under all experimental conditions, are reported in Table 2 . The $C_{\mathrm{r}}$ straight
Table 1 Participant characteristics

\begin{tabular}{|c|c|c|c|}
\hline & Total & Boys & Girls \\
\hline$n$ & 19 & 9 & 10 \\
\hline Age, years & $10.1 \pm 0.5$ & $10.2 \pm 0.6$ & $10.0 \pm 0.3$ \\
\hline Tanner stages, $\%$ & $\begin{array}{r}60 \% \mathrm{~T} 1,20 \% \\
\mathrm{~T} 2,20 \% \mathrm{~T} 3\end{array}$ & $\begin{array}{r}30 \% \mathrm{~T} 1,40 \% \\
\mathrm{~T} 2,30 \% \mathrm{~T} 3\end{array}$ & $90 \% \mathrm{~T} 1,10 \% \mathrm{~T} 3$ \\
\hline Years to PHV, years & $-2.4 \pm 0.8$ & $-3.03 \pm 0.3$ & $-1.9 \pm 0.6$ \\
\hline Stature, $\mathrm{m}$ & $1.39 \pm 0.07$ & $1.42 \pm 0.05$ & $1.38 \pm 0.09^{\mathrm{a}}$ \\
\hline Body mass, $\mathrm{kg}$ & $33.7 \pm 5.7$ & $35.03 \pm 3.8$ & $32.6 \pm 7.0^{\mathrm{a}}$ \\
\hline BMI, $\mathrm{kg} \mathrm{m}^{-2}$ & $17.1 \pm 2.3$ & $17.3 \pm 1.7$ & $17.2 \pm 2.8$ \\
\hline Peak $\dot{V} \mathrm{O}_{2}, 1 \mathrm{~min}^{-1}$ & $1.63 \pm 0.39$ & $1.79 \pm 0.44$ & $1.49 \pm 0.29^{\mathrm{a}}$ \\
\hline $\begin{array}{l}\text { Scaled peak } \dot{V} \mathrm{O}_{2} \\
1 \mathrm{~kg}^{-0.79} \mathrm{~min}^{-1}\end{array}$ & $100.8 \pm 18.8$ & $98.8 \pm 17.4$ & $102.5 \pm 20.7^{\mathrm{a}}$ \\
\hline GET, $1 \min ^{-1}$ & $1.03 \pm 0.25$ & $1.17 \pm 0.25$ & $0.90 \pm 0.18$ \\
\hline
\end{tabular}

Mean \pm SD

$P H V$ peak height velocity, $T 1$ Tanner stage 1, T2 Tanner stage 2, T3 Tanner stage $3, B M I$ body mass index, $\dot{V} \mathrm{O}_{2}$ oxygen uptake, GET gas exchange threshold

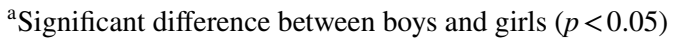

$\left(0^{\circ}\right)$ decreases with speed to attain a significant $(p<0.006)$ minimum energy expenditure at $5.5 \mathrm{~km} \mathrm{~h}^{-1}$ compared to $2.5 \mathrm{~km} \mathrm{~h}^{-1}$. The effect of $45^{\circ}$ and $90^{\circ}$ turns on $C_{\mathrm{r}}$ is relatively minor. However, $180^{\circ}$ turns at speeds 3.5 , and $5.5 \mathrm{~km} \mathrm{~h}^{-1}$, significantly greater $C_{\mathrm{r}}(p<0.006)$ were established when compared to straight-line walking within speeds. More specifically, for a $180^{\circ}$ angle, speed increased $C_{\mathrm{r}}$ by $\sim 7 \%$ at $2.5 \mathrm{~km} \mathrm{~h}^{-1}$, to $\sim 13 \%$ at $3.5 \mathrm{~km} \mathrm{~h}^{-1}(p<0.006)$, $\sim 14 \%$ at $4.5 \mathrm{~km} \mathrm{~h}^{-1}$, to attain $\sim 30 \%$ increase at $5.5 \mathrm{~km} \mathrm{~h}^{-1}$ $(p<0.006)$.

Participants' mean absolute and scaled $\dot{V} \mathrm{O}_{2}$ are reported in Table 3. There was a significant main effect for speed $(F=101.13, p<0.006)$ and turn angle $(F=11.52, p<0.006)$ on absolute $\dot{V} \mathrm{O}_{2}$, with no significant interaction between speed and angle $(F=2.01, p>0.006$; Table 5, see "Appendix"), with similar effects still observed when scaled to account for body size (speed, $F=106.30, p<0.006$; angle, $F=13.96, p<0.006$; speed and angle, $F=168.14$, $p>0.006)$. As shown in Fig. 3, increasing speed was found to increase $\dot{V} \mathrm{O}_{2}$ within a turn angle, but significant increases in $\dot{V} \mathrm{O}_{2}$ due to turning relative to straight-line walking were only observed at $180^{\circ}$ at the highest speed. There were no significant differences between boys and girls $\dot{V} \mathrm{O}_{2}$ across all conditions $(F=6.26, p>0.006)$, regardless of the method of expression for $\dot{V} \mathrm{O}_{2}$. Stature $(F=26.27, p<0.006)$ and $\dot{V} \mathrm{O}_{2 \text { peak }}(F=24.53, p<0.006)$ were significant predictors of $\dot{V} \mathrm{O}_{2}$ during each condition for both sexes, although when condition $\dot{V} \mathrm{O}_{2}$ was scaled, scaled $\dot{V} \mathrm{O}_{2 \text { peak }}$ was no longer a significant predictor $(F=0.98, p>0.006)$. The significant predictors for absolute and scaled $\dot{V} \mathrm{O}_{2}$ models on speed, angle, and their interaction are shown in Table 5 (see "Appendix"). 
Table 2 Values for net energy cost of walking and turning
Table 3 Mean energy expenditure during each combination of walking velocity and angle

\begin{tabular}{|c|c|c|c|c|}
\hline \multirow[t]{2}{*}{ Speed $\left(\mathrm{km} \mathrm{h}^{-1}=\mathrm{m} \mathrm{min}^{-1}\right)$} & \multicolumn{4}{|c|}{$\dot{V} \mathrm{O}_{2}\left(C_{\mathrm{r}}, \mathrm{ml} \mathrm{O}_{2} \mathrm{~kg}^{-1} \mathrm{~km}^{-1}\right)$} \\
\hline & $0^{\circ}$ & $45^{\circ}$ & $90^{\circ}$ & $180^{\circ}$ \\
\hline $2.5=41.67$ & $0.28 \pm 0.05$ & $0.29 \pm 0.05$ & $0.30 \pm 0.05$ & $0.30 \pm 0.06$ \\
\hline $3.5=58.33$ & $0.23 \pm 0.04^{\mathrm{a}}$ & $0.23 \pm 0.04^{\mathrm{a}}$ & $0.24 \pm 0.04^{\mathrm{a}}$ & $0.26 \pm 0.05^{\mathrm{b}}$ \\
\hline $4.5=75.00$ & $0.21 \pm 0.04^{\mathrm{a}}$ & $0.21 \pm 0.04^{\mathrm{a}}$ & $0.21 \pm 0.04^{\mathrm{a}}$ & $0.24 \pm 0.04^{\mathrm{a}}$ \\
\hline $5.5=91.67$ & $0.20 \pm 0.04^{\mathrm{a}}$ & $0.20 \pm 0.03^{\mathrm{a}}$ & $0.20 \pm 0.04^{\mathrm{a}}$ & $0.26 \pm 0.04^{\mathrm{b}}$ \\
\hline
\end{tabular}

Mean \pm SD

$\dot{V} \mathrm{O}_{2}$ oxygen uptake

${ }^{\text {a }}$ Significant difference to $2.5 \mathrm{~km} \mathrm{~h}^{-1}$ within angle $(p<0.006)$

${ }^{\mathrm{b}}$ Significant difference to straight-line walking within speed $(p<0.006)$

\begin{tabular}{|c|c|c|c|c|}
\hline & $0^{\circ}$ & $45^{\circ}$ & $90^{\circ}$ & $180^{\circ}$ \\
\hline \multicolumn{5}{|c|}{ Absolute $\dot{V} \mathrm{O}_{2}\left(1 \mathrm{~min}^{-1}\right)$} \\
\hline $2.5 \mathrm{~km} \mathrm{~h}^{-1}$ & $0.40 \pm 0.10$ & $0.40 \pm 0.10$ & $0.42 \pm 0.10$ & $0.42 \pm 0.10$ \\
\hline $3.5 \mathrm{~km} \mathrm{~h}^{-1}$ & $0.44 \pm 0.11^{\mathrm{a}}$ & $0.44 \pm 0.10$ & $0.47 \pm 0.11$ & $0.50 \pm 0.13^{\mathrm{a}, \mathrm{b}}$ \\
\hline $4.5 \mathrm{~km} \mathrm{~h}^{-1}$ & $0.52 \pm 0.11^{\mathrm{a}}$ & $0.51 \pm 0.12^{\mathrm{a}}$ & $0.53 \pm 0.11^{\mathrm{a}}$ & $0.60 \pm 0.15^{\mathrm{a}, \mathrm{b}}$ \\
\hline $5.5 \mathrm{~km} \mathrm{~h}^{-1}$ & $0.62 \pm 0.13^{\mathrm{a}}$ & $0.60 \pm 0.13^{\mathrm{a}}$ & $0.63 \pm 0.15^{\mathrm{a}}$ & $0.75 \pm 0.17^{\mathrm{a}, \mathrm{b}}$ \\
\hline \multicolumn{5}{|c|}{ Scaled $\dot{V} \mathrm{O}_{2}\left(1 \mathrm{~kg}^{-0.79} \min ^{-1}\right)$} \\
\hline $2.5 \mathrm{~km} \mathrm{~h}^{-1}$ & $24.75 \pm 4.40$ & $25.08 \pm 4.40$ & $26.25 \pm 4.34$ & $26.00 \pm 4.99$ \\
\hline $3.5 \mathrm{~km} \mathrm{~h}^{-1}$ & $27.62 \pm 5.18^{\mathrm{a}}$ & $27.56 \pm 5.14$ & $29.27 \pm 4.58^{\mathrm{a}}$ & $31.26 \pm 6.06^{\mathrm{a}}$ \\
\hline $4.5 \mathrm{~km} \mathrm{~h}^{-1}$ & $32.84 \pm 5.55^{\mathrm{a}}$ & $32.06 \pm 6.10^{\mathrm{a}}$ & $33.41 \pm 5.73^{\mathrm{a}}$ & $37.39 \pm 6.71^{\mathrm{a}}$ \\
\hline $5.5 \mathrm{~km} \mathrm{~h}^{-1}$ & $38.73 \pm 7.06^{\mathrm{a}}$ & $37.79 \pm 6.51^{\mathrm{a}}$ & $39.41 \pm 7.26^{\mathrm{a}}$ & $47.11 \pm 8.41^{\mathrm{a}, \mathrm{b}}$ \\
\hline
\end{tabular}

Mean \pm SD

$\dot{V} \mathrm{O}_{2}$ oxygen uptake

${ }^{\text {a }}$ Significant difference to $2.5 \mathrm{~km} \mathrm{~h}^{-1}$ within angle $(p<0.006)$

${ }^{\mathrm{b}}$ Significant difference to straight walking within speed $(p<0.006)$

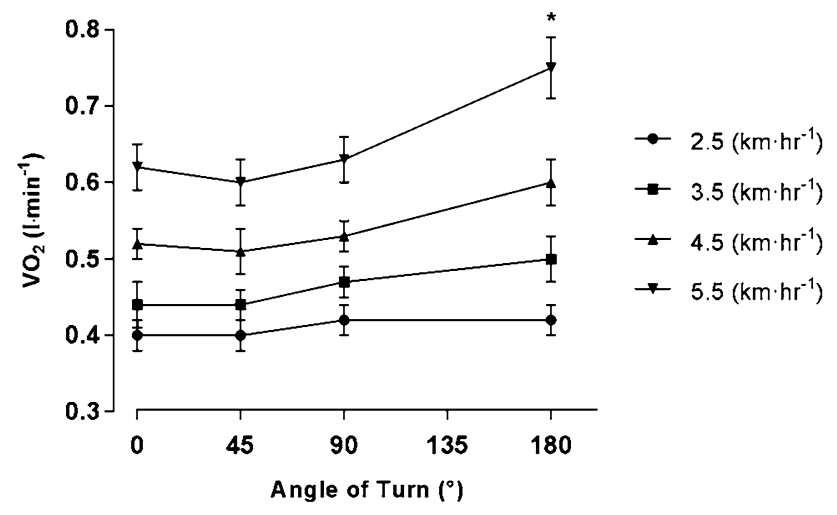

Fig. 3 Interaction between speed and angle on absolute $\dot{V} \mathrm{O}_{2}$, displaying SEM. 'Asterisk' indicates a significant difference in energy expenditure of turning relative to straight-line walking at $5.5 \mathrm{~km} \mathrm{~h}^{-1}$ $(p<0.006)$

A significant main effect was found for speed $(F=548.49$, $p<0.006)$ but not for angle $(F=3.66, p>0.006)$ on straight mean VeDBA, with significant effects found for both speed and angle on turn mean VeDBA (speed: $F=724.88$, $p<0.006$; angle: $F=4.96, p<0.006)$. Speed and angle had no significant interaction effect on mean VeDBA during either straight $(F=0.82, p>0.006)$ or turns $(F=0.99$, $p>0.006)$. Specifically, both straight and turning mean VeDBA increased with speed (Table 4), but no significant effects were found (Table 6, see "Appendix"). For straight walking VeDBA, there were no significant predictors (sex: $F=0.40, p>0.006 ; \dot{V} \mathrm{O}_{2 \text { peak }} F=2.62, p>0.006$; scaled $\left.\dot{V} \mathrm{O}_{2 \text { peak }} F=1.53, p>0.006\right)$, with turning VeDBA significantly predicted by sex $(F=14.20, p<0.006)$ with both $\dot{V} \mathrm{O}_{2 \text { peak }}(F=6.25, p>0.006)$ and scaled $\dot{V} \mathrm{O}_{2 \text { peak }}$ $(F=2.67, p>0.006)$ not significantly predicting (Table 6 , see "Appendix").

\section{Pearson product-moment correlation coefficient}

There were significant correlations between $\dot{V} \mathrm{O}_{2}$ and straight $\left(r^{2}=0.51 ; p<0.006\right)$ and turning $\operatorname{VeDBA}\left(r^{2}=0.54\right.$; $p<0.006$ ), with a weaker but statistically significant relationship between $\dot{V} \mathrm{O}_{2 \text { peak }}\left(r^{2}=0.30 ; p<0.006\right)$ and stature $\left(r^{2}=0.32 ; p<0.006\right)$. 
Table 4 Mean VeDBA, straight, and turn mean VeDBA during each combination of walking velocity and angle

\begin{tabular}{|c|c|c|c|c|}
\hline & $0^{\circ}$ & $45^{\circ}$ & $90^{\circ}$ & $180^{\circ}$ \\
\hline \multicolumn{5}{|c|}{ Mean VeDBA $(g)$} \\
\hline $2.5 \mathrm{~km} \mathrm{~h}^{-1}$ & $0.22 \pm 0.02$ & $0.21 \pm 0.02$ & $0.22 \pm 0.03$ & $0.22 \pm 0.03$ \\
\hline $3.5 \mathrm{~km} \mathrm{~h}^{-1}$ & $0.28 \pm 0.04^{\mathrm{a}}$ & $0.29 \pm 0.05^{\mathrm{a}}$ & $0.29 \pm 0.04^{\mathrm{a}}$ & $0.31 \pm 0.04^{\mathrm{a}, \mathrm{b}}$ \\
\hline $4.5 \mathrm{~km} \mathrm{~h}^{-1}$ & $0.41 \pm 0.07^{\mathrm{a}}$ & $0.40 \pm 0.07^{\mathrm{a}}$ & $0.41 \pm 0.07^{\mathrm{a}}$ & $0.44 \pm 0.06^{\mathrm{a}}$ \\
\hline $5.5 \mathrm{~km} \mathrm{~h}^{-1}$ & $0.60 \pm 0.10^{\mathrm{a}}$ & $0.59 \pm 0.11^{\mathrm{a}}$ & $0.59 \pm 0.13^{\mathrm{a}}$ & $0.63 \pm 0.11^{\mathrm{a}}$ \\
\hline \multicolumn{5}{|c|}{ Straight mean VeDBA $(g)$} \\
\hline $2.5 \mathrm{~km} \mathrm{~h}^{-1}$ & $0.21 \pm 0.02$ & $0.22 \pm 0.03$ & $0.22 \pm 0.03$ & $0.22 \pm 0.03$ \\
\hline $3.5 \mathrm{~km} \mathrm{~h}^{-1}$ & $0.29 \pm 0.05^{\mathrm{a}}$ & $0.29 \pm 0.04^{\mathrm{a}}$ & $0.31 \pm 0.04^{\mathrm{a}}$ & $0.32 \pm 0.05^{\mathrm{a}, \mathrm{b}}$ \\
\hline $4.5 \mathrm{~km} \mathrm{~h}^{-1}$ & $0.40 \pm 0.07^{\mathrm{a}}$ & $0.41 \pm 0.07^{\mathrm{a}}$ & $0.44 \pm 0.06^{\mathrm{a}}$ & $0.44 \pm 0.07^{\mathrm{a}}$ \\
\hline $5.5 \mathrm{~km} \mathrm{~h}^{-1}$ & $0.59 \pm 0.11^{\mathrm{a}}$ & $0.59 \pm 0.13^{\mathrm{a}}$ & $0.63 \pm 0.11^{\mathrm{a}}$ & $0.63 \pm 0.11^{\mathrm{a}}$ \\
\hline \multicolumn{5}{|c|}{ Turn mean VeDBA $(g)$} \\
\hline $2.5 \mathrm{~km} \mathrm{~h}^{-1}$ & $0.22 \pm 0.06^{\mathrm{a}}$ & $0.22 \pm 0.03$ & $0.22 \pm 0.03$ & $0.22 \pm 0.03$ \\
\hline $3.5 \mathrm{~km} \mathrm{~h}^{-1}$ & $0.30 \pm 0.07^{\mathrm{a}}$ & $0.30 \pm 0.05^{\mathrm{a}}$ & $0.29 \pm 0.05^{\mathrm{a}}$ & $0.31 \pm 0.06^{\mathrm{a}, \mathrm{b}}$ \\
\hline $4.5 \mathrm{~km} \mathrm{~h}^{-1}$ & $0.39 \pm 0.06^{\mathrm{a}}$ & $0.41 \pm 0.08^{\mathrm{a}}$ & $0.40 \pm 0.08^{\mathrm{a}}$ & $0.44 \pm 0.09^{\mathrm{a}}$ \\
\hline $5.5 \mathrm{~km} \mathrm{~h}^{-1}$ & $0.56 \pm 0.11^{\mathrm{a}}$ & $0.62 \pm 0.13^{\mathrm{a}}$ & $0.59 \pm 0.13^{\mathrm{a}}$ & $0.63 \pm 0.12^{\mathrm{a}}$ \\
\hline
\end{tabular}

Mean \pm SD

$V e D B A$ vectorial dynamic body acceleration

${ }^{\text {a }}$ Significant difference to $2.5 \mathrm{~km} \mathrm{~h}^{-1}$ within angle $(p<0.006)$

${ }^{\mathrm{b}}$ Significant difference to straight walking within speed $(p<0.006)$

\section{Discussion}

This is the first study to consider the energy expenditure of turning in children, demonstrating that as speed increases for any given angle of turn, the associated energy expenditure also increases. However, the extent to which angle contributed to an increased energetic demand was dependent upon the degree of the angle and walking speed. Specifically, increasing angles of turn and increasing walking speeds raised the energy expenditure, with $180^{\circ}$ turns requiring a significantly greater energy expenditure than $45^{\circ}$ or $90^{\circ}$ turns. The findings presented highlight the importance of accounting for the magnitude of turn angle and the frequency of turns completed when estimating the habitual physical activity and energy expenditure of children; a failure to do so is likely to lead to erroneous conclusions regarding daily energy expenditure estimated from accelerometry data.

Numerous studies have highlighted the importance of accounting for turning, as well as the physiological and the biomechanical effects of turning when compared to straight-line locomotion in adults (Akram et al. 2010; Buchheit et al. 2012; Dellal et al. 2010; Hatamoto et al. 2013, 2014; Huxham et al. 2006; Justine et al. 2014; Orendurff et al. 2006; Patla et al. 1999; Wilson et al. 2013). A recent study found that when shuttle run distance was reduced from 7.0 to $3.5 \mathrm{~m}$ and completed at the same average running speed, the $3.5 \mathrm{~m}$ shuttles induced a greater physiological response (Bekraoui et al. 2012).
Hatamoto et al. (2014) found that this greater physiological demand occurred even during walking velocities as low as $3 \mathrm{~km} \mathrm{~h}^{-1}$. The present study extends these findings to children, demonstrating that $C_{\mathrm{r}}$ in a straight line decreased with speed to a minimum energy expenditure attained at $5.5 \mathrm{~km} \mathrm{~h}^{-1}\left(1.5 \mathrm{~m} \mathrm{~s}^{-1}\right)$. These findings align with the previous research, highlighting that human walking displays a U-shaped relationship between walking speed and energy expenditure of transport (Sparrow 2000; Willis et al. 2005). The optimal speed of walking is frequently cited to be between $4.8\left(1.3 \mathrm{~m} \mathrm{~s}^{-1}\right)$ and $6 \mathrm{~km} \mathrm{~h}^{-1}\left(1.7 \mathrm{~m} \mathrm{~s}^{-1}\right)$, in which the energy expenditure per unit distance travelled is minimised (Bastien et al. 2005; Zarrugh et al. 1974). Furthermore, the present findings regarding $C_{r}$ to straight-line walking can be closely matched to Waters and Mulroy “s (1999) regression equation for children's $\dot{V O}_{2}$ by dividing the walking speed by $\mathrm{m} / \mathrm{min}$ (following: $\dot{V} \mathrm{O}_{2}$ cost $=0.188+2.61 / S$ ).

More importantly, the current findings showed that $180^{\circ}$ turns had a significantly greater energy expenditure per unit body mass and distance within speeds $3.5 \mathrm{~km} \mathrm{~h}^{-1}$ and $5.5 \mathrm{~km} \mathrm{~h}^{-1}$ exhibiting a $13 \%$ and $30 \%$ increase in energy expenditure, respectively, when compared to straight-line walking at the same speed. The resultant increase in energy expenditure of a $180^{\circ}$ turn could be partly explained by the greater braking (deceleration) and propulsive (acceleration) forces encountered during turning (Schot et al. 1995). Specifically, Schot et al. (1995) found that a $90^{\circ}$ turn experiences a greater acceleration phase, because an individual has to begin moving from a near stand-still position, whereas a $45^{\circ}$ turn encompasses some of the residual incoming motion prior to the turn. According to Havens and Sigward (2015), larger turn angles lead to greater alterations for both deceleration and translation subtasks. Therefore, it could be postulated that a greater angle, such as a $180^{\circ}$ turn, would experience larger deceleration and accelerations (Havens and Sigward 2015). As such, these findings may, in part, explain why paediatric populations with neuromuscular pathologies have trouble in turning, given their postural stability problems (Kenis-Coskun et al. 2016). In contrast, a recent study investigating the metabolic power of turning in youth soccer players concluded that turning $\left(45^{\circ}\right.$ and $\left.90^{\circ}\right)$, while running is less metabolically demanding than straightline running (Hader et al. 2016). It was concluded that this lower metabolic demand of turning may have been directly related to the very low energy demands of the deceleration phase during the turn that may not be compensated by the increased requirement for the re-acceleration phase. However, the study was limited using an indirect approach to estimate the energy demands of turning, which may ignore other non-locomotor muscles involved with turning (e.g., upper body and back muscles; Buchheit et al. 2010a, b). More research is warranted to investigate and strengthen 
our understanding of the energy expenditure associated with turning in child populations.

It is important to acknowledge that children are not "miniadults" (Armstrong and Welsman 1997), mostly due to their anatomical and physiological differences when compared to adults (Andropoulos 2012). Given these biomechanical and physiological differences are likely to influence the energy expenditure of turning in children, the applicability of the previous findings in adults to children must be questioned, even though the physics of force generation needed for turns makes increased energy expenditure in a turn inevitable. More specifically, however, covariates such as age, stature, training status, and turning technique (Buchheit et al. 2011; Zadro et al. 2011) may have a significant role in determining the energy expenditure associated with any given task and may lead to discrepancies when comparing adults to children. McNarry et al. (2017) reported a synergistic interaction between speed and angle, with $90^{\circ}$ and $180^{\circ}$ turns associated with a significantly greater energy cost at walking speeds of 4.5 and $5.5 \mathrm{~km} \mathrm{~h}^{-1}$. In comparison, the present study revealed that there was no significant interaction between speed and angle, although there was a trend similar to that of the adults, with a walking speed of $5.5 \mathrm{~km} \mathrm{~h}^{-1}$ at $180^{\circ}$ turn associated with the greatest energy expenditure when compared to all other combinations. In more detail, the mean $\dot{V} \mathrm{O}_{2}$ for an adult turning $180^{\circ}$ at a speed of $5.5 \mathrm{~km} \mathrm{~h}^{-1}$ was $1.54 \pm 0.361 \mathrm{~min}^{-1}$ (McNarry et al. 2017), which is substantially more than the value observed in the present study of $0.75 \pm 0.171 \mathrm{~min}^{-1}$. This discrepancy may be explained by the much larger stature of adults when compared to young children. Adults larger skeletal structure and muscle size is likely to change the moment arm length, both of which will result in increased energy costs (O'Brien et al. 2009). As Buchheit et al. (2011) found that shorter team sport players demonstrated less effect of a $180^{\circ}$ change of direction than their taller counterparts. Lower angles of turn are associated with greater balance and stability as a proper support base is established, therefore, requiring less energy to turn (Justine et al. 2014). This is demonstrated in the present study, whereby children's stature was a significant predictor for estimating the energy expenditure of turning, as supported by a similar relationship within adults (McNarry et al. 2017). It could, therefore, be postulated that children's shorter moment arms and lower centre of gravity would lead to a reduced energy expenditure of turning when compared to taller adults.

The ability to maintain balance is essential for carrying out activities such as walking and a crucial component while turning. Dynamic postural control (i.e., balance) is defined as the ability to keep the centre of gravity within the base of support while performing a task in a stable condition (Winter et al. 1990). The previous studies observe deficits in postural control in children when compared to young healthy adults (Bosco and Komi 1980; Hytönen et al. 1993; Schärli et al. 2013), potentially due to a smaller base of support, which would be anticipated to be associated with a greater energy expenditure during turning. Furthermore, Geldhof et al. (2006) found better postural control in girls compared to boys between the ages of 9-10 years, which could explain the sex differences observed in the present study. As described by Hase and Stein (1999), there are two types of turn embedded into locomotion, one being the step turn and the other the spin turn. Step turns are biomechanically more efficient (Patla et al. 1991; Taylor et al. 2005) and offer greater stability (Taylor et al. 2005) than spin turns. When observing turning strategies in adult populations, step turns are most commonly reported in both laboratory (Patla et al. 1991) and non-laboratory environments (i.e., home or community; Glaister et al. 2007). Although findings from Dixon et al. (2013) is limited to laboratory settings, evidence suggests that children tend to adopt spin turns, with this adoption likely to be dependent on increasing gait velocity. Research suggests that spin turns limit the size of the moving base of support (Akram et al. 2010), which consequently leads to reduced stability, increasing the physiological strain on both lower limb (Hader et al. 2016) and upper body muscles (Buchheit et al. 2010). Therefore, it could be postulated that the increasing demands of a turn, such as a $180^{\circ}$ at a speed of $5.5 \mathrm{~km} \mathrm{~h}^{-1}$, may expose children's gait immaturity and concurrently lead to the adoption of the more complex turning sub-strategies identified within adult populations (Dixon et al. 2013). Although turning strategies and dynamic postural control were not accounted for in the present study, it is important to consider that turning strategies may have varied between children, affecting balance and consequently the variance of the values observed for energy expenditure. Therefore, further work on the energy expenditure of spin and step turn strategies is warranted in non-laboratory-based environments.

Some of the present study's findings have implications for assessing children's movement patterns in both habitual and health contexts. As highlighted by McNarry et al. (2017), it is important to account for the number of turns during a clinical six-minute walking test (6MWT), designed to measure both adults' (Veloso-Guedes et al. 2011) and children's (Geiger et al. 2007) functional exercise capacity. McNarry et al. (2017) highlight that the 6MWT varies due to limited space and resources, which consequently results in distances ranging from 20 to $50 \mathrm{~m}$ being used (Lipkin et al. 1986; Troosters et al. 1999), subsequently altering the frequency of turns completed from as much as 12 to 32 turns (Chetta et al. 2006). These methodological differences are likely to affect the reliability of aerobic capacity assessment using this method, especially for paediatric populations which have a restricted gait ability, such as those with cerebral palsy who show greater physiological cost of walking compared 
to healthy children (Liao et al. 1997). Nevertheless, a more recent study suggested that slow jogging with turns could be an effective exercise prescription to promote physical activity and fitness in inactive-healthy individuals and those who are overweight or obese. Specifically, Araki et al. (2017) demonstrated that walking at $4.2 \mathrm{~km} \mathrm{~h}^{-1}$, that is equal to 3 METs (light-intensity), to jogging at the same speed with turns, increased the intensity to 8 METs (vigorous intensity), which resulted in a 2.7-fold increase in energy expenditure. Moreover, Araki et al. (2017a, b) showed that slow walking $\left(2.7 \mathrm{~km} \mathrm{~h}^{-1}\right.$ ) became moderately intense (4 METs) when turns were incorporated. Therefore, including turns may be an effective method by which to increase the amount of physical activity that inactive individuals perform, to lose weight and increase fitness. However, there is a paucity of evidence to support the use of turning as a health promotion intervention, especially in children, therefore, warranting further investigation.

The findings in the present study question the previously assessed and validated accuracy of pedometers, gyroscopes, and accelerometers (Crouter et al. 2003; Esliger et al. 2007; Le Masurier and Tudor-Locke 2003; Mansfield and Lyons 2003; Rueterbories et al. 2010; Salarian et al. 2004), as the majority of the protocols performed during these studies have been relatively simple, with long periods of linear treadmill-based locomotion that are not true to the nature of habitual physical activity patterns. Indeed, these treadmillbased prediction equations may be a contributing factor to the poor accuracy of energy expenditure calculations during daily activities (Eisenmann et al. 2004; Fortune et al. 2014). In this respect, the magnetometer utilized in the present study provides additional information on how the body rotates (Williams et al. 2017), so when in conjunction with accelerometers, it will provide more context. Indeed, using the current methods to establish VeDBA from analysing the accelerometer and magnetometer traces proved to be relatively accurate in predicting energy expenditure expressed as $\dot{V} \mathrm{O}_{2}$, aligning with the previous research (McNarry et al. 2017; Qasem et al. 2012; Weippert et al. 2013). However, from the present findings, it is apparent that there is a dissociation between VeDBA and turn angle, whereby increasing the angle of turn was not associated with significant increase in VeDBA. Similar findings were reported in adults by McNarry et al. (2017) arguing that this dissociation of VeDBA when turning could be a result of the complex and individual specific interaction between the surge, heave, and sway components of DBA as well as the muscular effort involved in generating forces without the dynamism of straight locomotion. Although little is known about the benefits of including such magnetometry-derived data on the accuracy of energy expenditure prediction, the present study highlights this collective measurement as an area that warrants further investigation, especially in children who are characterised by spontaneous and transitory movement patterns (Stone et al. 2009), such as football (Fjørtoft et al. 2009) and chasing games (Sleap and Warburton 1996) that likely involve a considerable number of turns.

It is important to note certain limitations of the current study. As this was the first study to investigate the energy expenditure of turning in children, findings should be taken with caution, due to the limited sample size and lack of evidence on the influence of children's growth and maturation on the energy demands of turning, warranting further investigation. In addition, the highly controlled nature of this study may limit the generalisability of the findings and its ecological validity.

\section{Conclusions}

In the present study, we found that the energy expenditure of turning, while walking was significantly greater at speeds of $3.5,4.5$ and $5.5 \mathrm{~km} \mathrm{~h}^{-1}$ at a turn angle of $180^{\circ}$ in children. The study demonstrated the impact of turn angle and walking speeds on the energy expenditure of turning, with stature adding additional determinants of the demand. More research is warranted on running speeds and the effect of turning technique on the energy expenditure of turning. These findings highlight the importance of accounting for the costs of turning in children, with implications for both sporting, habitual physical activity, and health-related contexts, where turning is a fundamental part of movement.

Acknowledgements The authors thank all of the teachers and parents for their help and the children who participated in the study. We would also like to thank the Sport Wales Illuminate fund for supporting the research and making it possible.

Author contributions MAM, KAM, RPW, and IWG conceived of and designed the experiments; SGMC and MAM performed the experiments; SGMC, MAM, KAM, and LL analyzed the data; all authors contributed to the interpretation of the data; the first draft was written by SGMC; and all authors provided critical input and revisions. All authors read and approved the final manuscript.

Funding The study was supported by the Sport Wales Illuminate fund (Grant number: RES/SJ/ILLUMINATE/04).

\section{Compliance with ethical standards}

Conflict of interest The authors declare that they have no conflicts of interest.

Ethical approval The study was performed in accordance with ethical standards of the Declaration of Helsinki. Approval to conduct this research was granted by Swansea University A-STEM Ethical Advisory Committee (reference number: PG/2014/16).

Informed consent Informed consent was obtained from all individual participants included in the study. 
Open Access This article is distributed under the terms of the Creative Commons Attribution 4.0 International License (http://creativeco mmons.org/licenses/by/4.0/), which permits unrestricted use, distribution, and reproduction in any medium, provided you give appropriate credit to the original author(s) and the source, provide a link to the Creative Commons license, and indicate if changes were made.

\section{Appendix}

See Tables 5 and 6.
Table 5 Absolute and scaled $\dot{\mathrm{V}} \mathrm{O}_{2}$ models

\begin{tabular}{|c|c|c|c|c|c|c|}
\hline & \multicolumn{3}{|c|}{ Absolute $\dot{V} \mathrm{O}_{2}\left(1 \mathrm{~min}^{-1}\right)$} & \multicolumn{3}{|c|}{ Scaled $\dot{V} \mathrm{O}_{2}\left(1 \mathrm{~kg}^{-0.79} \mathrm{~min}^{-1}\right)$} \\
\hline & Estimate $(\beta)$ & SE & Sig. & Estimate $(\beta)$ & SE & Sig. \\
\hline Parameter & Speed & & & & & \\
\hline $5.5 \mathrm{~km} \mathrm{~h}^{-1}$ & 0.23 & 0.03 & 0.007 & 13.87 & 1.95 & $0.00^{\mathrm{a}}$ \\
\hline $4.5 \mathrm{~km} \mathrm{~h}^{-1}$ & 0.14 & 0.02 & $0.00^{\mathrm{a}}$ & 8.78 & 1.48 & $0.00^{\mathrm{a}}$ \\
\hline $3.5 \mathrm{~km} \mathrm{~h}^{-1}$ & 0.07 & 0.02 & $0.002^{\mathrm{a}}$ & 4.06 & 1.19 & $0.00^{\mathrm{a}}$ \\
\hline $2.5 \mathrm{~km} \mathrm{~h}^{-1}$ & 1.00 & - & - & 1.00 & - & - \\
\hline Parameter & Angle & & & & & \\
\hline $180^{\circ}$ & 0.02 & 0.02 & 0.38 & 1.26 & 1.39 & 0.37 \\
\hline $90^{\circ}$ & 0.03 & 0.02 & 0.10 & 2.68 & 1.17 & 0.03 \\
\hline $45^{\circ}$ & 0.10 & 0.02 & 0.62 & 0.89 & 1.20 & 0.46 \\
\hline $0^{\circ}$ & 1.00 & - & - & 1.00 & - & - \\
\hline Parameter & Speed $\times$ angle & & & & & \\
\hline Speed $5.5 \times$ angle $180^{\circ}$ & 0.14 & 0.05 & $0.005^{\mathrm{a}}$ & 8.84 & 2.89 & $0.003^{\mathrm{a}}$ \\
\hline Speed $5.5 \times$ angle $90^{\circ}$ & -0.32 & 0.04 & 0.48 & -1.95 & 2.65 & 0.46 \\
\hline Speed $5.5 \times$ angle $45^{\circ}$ & -0.02 & 0.04 & 0.67 & -1.01 & 2.60 & 0.70 \\
\hline Speed $5.5 \times$ angle $0^{\circ}$ & 1.00 & - & - & 1.00 & - & - \\
\hline Speed $4.5 \times$ angle $180^{\circ}$ & 0.05 & 0.04 & 0.17 & 3.59 & 2.27 & 0.12 \\
\hline Speed $4.5 \times$ angle $90^{\circ}$ & -0.03 & 0.03 & 0.40 & -2.11 & 2.06 & 0.31 \\
\hline Speed $4.5 \times$ angle $45^{\circ}$ & -0.02 & 0.03 & 0.50 & -1.33 & 2.07 & 0.52 \\
\hline Speed $4.5 \times$ angle $0^{\circ}$ & 1.00 & - & - & 1.00 & - & - \\
\hline Speed $3.5 \times$ angle $180^{\circ}$ & 0.41 & 0.03 & 0.19 & 2.77 & 1.82 & 0.13 \\
\hline Speed $3.5 \times$ angle $90^{\circ}$ & -0.02 & 0.03 & 0.52 & -1.15 & 1.66 & 0.49 \\
\hline Speed $3.5 \times$ angle $45^{\circ}$ & -0.02 & 0.03 & 0.57 & -1.58 & 1.73 & 0.36 \\
\hline Speed $3.5 \times$ angle $0^{\circ}$ & 1.00 & - & - & 1.00 & - & - \\
\hline Parameter & Sex & & & & & \\
\hline Girl & -0.02 & 0.01 & 0.01 & -1.48 & 0.55 & 0.008 \\
\hline Boy & 1.00 & - & - & 1.00 & - & - \\
\hline Parameter & Covariates & & & & & \\
\hline Stature & 0.00 & 0.00 & $0.00^{\mathrm{a}}$ & 0.08 & 0.04 & 0.04 \\
\hline Peak $\dot{V} \mathrm{O}_{2}$ & 0.08 & 0.02 & $0.00^{\mathrm{a}}$ & - & - & - \\
\hline Scaled $\dot{V} \mathrm{O}_{2 \text { peak }}$ & - & - & - & -0.01 & 0.01 & 0.32 \\
\hline
\end{tabular}

Reference values speed $2.5 \mathrm{~km} \mathrm{~h}^{-1}$ and angle set at $0^{\circ}$. ' $\times$ ' Indicates interaction

${ }^{\text {a }}$ Significant effect at $(p<0.006)$ 
Table 6 Straight and turn mean VeDBA models

\begin{tabular}{|c|c|c|c|c|c|c|}
\hline & \multicolumn{3}{|c|}{ Straight mean VeDBA $(g)$} & \multicolumn{3}{|c|}{ Turn mean VeDBA $(g)$} \\
\hline & Estimate $(\beta)$ & SE & Sig. & Estimate $(\beta)$ & SE & Sig. \\
\hline Parameter & Speed & & & & & \\
\hline $5.5 \mathrm{~km} \mathrm{~h}^{-1}$ & 0.35 & 0.02 & $0.00^{\mathrm{a}}$ & 0.38 & 0.02 & $0.00^{\mathrm{a}}$ \\
\hline $5.5 \mathrm{~km} \mathrm{~h}^{-1}$ & 0.18 & 0.02 & $0.00^{\mathrm{a}}$ & 0.19 & 0.01 & $0.00^{\mathrm{a}}$ \\
\hline $5.5 \mathrm{~km} \mathrm{~h}^{-1}$ & 0.07 & 0.02 & $0.00^{\mathrm{a}}$ & 0.06 & 0.01 & $0.00^{\mathrm{a}}$ \\
\hline $5.5 \mathrm{~km} \mathrm{~h}^{-1}$ & 1.00 & - & - & 1.00 & - & - \\
\hline Parameter & & & Angle & & & \\
\hline $180^{\circ}$ & 0.001 & 0.01 & 0.94 & 0.008 & 0.01 & 0.25 \\
\hline $90^{\circ}$ & -0.002 & 0.01 & 0.86 & 0.000 & 0.01 & 0.98 \\
\hline $45^{\circ}$ & -0.001 & 0.01 & 0.93 & -0.003 & 0.01 & 0.66 \\
\hline $0^{\circ}$ & 1.00 & - & - & 1.00 & - & - \\
\hline Parameter & Speed $\times$ angle & & & & & \\
\hline Speed $5.5 \times$ angle $180^{\circ}$ & 0.06 & 0.03 & 0.04 & 0.01 & 0.03 & 0.60 \\
\hline Speed $5.5 \times$ angle $90^{\circ}$ & 0.02 & 0.03 & 0.50 & -0.01 & 0.03 & 0.69 \\
\hline Speed $5.5 \times$ angle $45^{\circ}$ & 0.04 & 0.03 & 0.19 & -0.01 & 0.03 & 0.77 \\
\hline Speed $5.5 \times$ angle $0^{\circ}$ & 1.00 & - & - & 1.00 & - & - \\
\hline Speed $4.5 \times$ angle $180^{\circ}$ & 0.04 & 0.02 & 0.09 & 0.03 & 0.02 & 0.19 \\
\hline Speed $4.5 \times$ angle $90^{\circ}$ & 0.01 & 0.02 & 0.77 & -0.008 & 0.02 & 0.69 \\
\hline Speed $4.5 \times$ angle $45^{\circ}$ & 0.02 & 0.02 & 0.42 & -0.002 & 0.02 & 0.92 \\
\hline Speed $4.5 \times$ angle $0^{\circ}$ & 1.00 & - & - & 1.00 & - & - \\
\hline Speed $3.5 \times$ angle $180^{\circ}$ & 0.01 & 0.02 & 0.51 & 0.03 & 0.01 & 0.02 \\
\hline Speed $3.5 \times$ angle $90^{\circ}$ & 0.00 & 0.02 & 0.91 & 0.01 & 0.01 & 0.36 \\
\hline Speed $3.5 \times$ angle $45^{\circ}$ & 0.01 & 0.02 & 0.59 & 0.01 & 0.01 & 0.31 \\
\hline Speed $3.5 \times$ angle $0^{\circ}$ & 1.00 & - & - & 1.00 & - & - \\
\hline Parameter & Sex & & & & & \\
\hline Girl & 0.003 & 0.01 & 0.53 & 0.02 & 0.00 & $0.00^{\mathrm{a}}$ \\
\hline Boy & 1.00 & - & - & 1.00 & - & - \\
\hline Parameter & Covariates & & & & & \\
\hline Peak $\dot{V} \mathrm{O}_{2}$ & -0.01 & 0.01 & 0.11 & - & - & - \\
\hline Scaled $\dot{V} \mathrm{O}_{2 \text { peak }}$ & - & - & - & 0.0002 & 0.0001 & 0.10 \\
\hline
\end{tabular}

Reference values speed $2.5 \mathrm{~km} \mathrm{~h}^{-1}$ and angle set at $0^{\circ}$. ' $\times$ ' Indicates interaction

${ }^{\text {a }}$ Significant effect at $(p<0.006)$

\section{References}

Akram SB, Frank JS, Chenouri S (2010) Turning behavior in healthy older adults: is there a preference for step versus spin turns? Gait Posture 31:23-26. https://doi.org/10.1016/j.gaitpost.2009.08.238

Andropoulos DB (2012) Pediatric physiology: how does it differ from adults? In: Mason KP (ed) Pediatric sedation outside of the operating room: a multispecialty international collaboration. Springer, New York, pp 77-91. https://doi. org/10.1007/978-0-387-09714-5_7

Araki M, Hatamoto Y, Higaki Y, Tanaka H (2017a) "Slow walking with turns" increases quadriceps and erector spinae muscle activity. J Phys Ther Sci 29:419-424. https://doi.org/10.1589/ jpts.29.419

Araki M, Hatamoto Y, Takae R, Jackowska M, Tanaka H (2017b) Turns in jogging increase energy expenditure: proposed home exercise for sedentary people. J Nov Physiother. https://doi. org/10.4172/2165-7025.1000360

Armstrong N, Welsman J (1997) Young people and physical activity. Oxford University Press, Oxford
Baquet G, Stratton G, Van Praagh E, Berthoin S (2007) Improving physical activity assessment in prepubertal children with high-frequency accelerometry monitoring: a methodological issue. Prev Med 44:143-147. https://doi.org/10.1016/j.ypmed .2006.10.004

Bassett DR, John D (2010) Use of pedometers and accelerometers in clinical populations: validity and reliability issues. Phys Ther Rev 15:135-142. https://doi.org/10.1179/1743288X10Y.00000 00004

Bastien GJ, Willems PA, Schepens B, Heglund NC (2005) Effect of load and speed on the energetic cost of human walking. Eur J Appl Physiol 94:76-83. https://doi.org/10.1007/s0042 1-004-1286-Z

Beaver WL, Wasserman K, Whipp BJ (1986) A new method for detecting anaerobic threshold by gas exchange. J Appl Physiol 60:2020-2027

Bekraoui N, Fargeas-Gluck M-A, Léger L (2012) Oxygen uptake and heart rate response of 6 standardized tennis drills. Appl Physiol Nutr Metab 37:982-989. https://doi.org/10.1139/h2012-082

Bidder OR, Qasem LA, Wilson RP (2012) On higher ground: how well can dynamic body acceleration determine speed in variable 
terrain? PLoS One 7:e50556. https://doi.org/10.1371/journ al.pone.0050556

Bosco C, Komi PV (1980) Influence of aging on the mechanical behavior of leg extensor muscles. Eur J Appl Physiol Occup Physiol 45:209-219

Buchheit M, Bishop D, Haydar B, Nakamura FY, Ahmaidi S (2010a) Physiological responses to shuttle repeated-sprint running. Int J Sports Med 31:402-409

Buchheit M, Bishop D, Haydar B, Nakamura FY, Ahmaidi S (2010b) Physiological responses to shuttle repeated-sprint running. Int J Sports Med 31:402-409. https://doi.org/10.1055/s-0030-12496 20

Buchheit M, Haydar B, Hader K, Ufland P, Ahmaidi S (2011) Assessing running economy during field running with changes of direction: application to $20 \mathrm{~m}$ shuttle runs. Int J Sports Physiol Perform 6:380-395

Buchheit M, Haydar B, Ahmaidi S (2012) Repeated sprints with directional changes: do angles matter? J Sports Sci 30:555-562. https ://doi.org/10.1080/02640414.2012.658079

Chan NP, Sung RY, Nelson EA, So HK, Tse YK, Kong AP (2010) Measurement of pubertal status with a Chinese self-report Pubertal Development Scale. Maternal Child Health J 14:466-473. https://doi.org/10.1007/s10995-009-0481-2

Chen KY, Rothney MP, Brychta RJ (2007) Physical activity monitors: do more sensors mean better precision? J Diabetes Sci Technol (Online) 1:768-770

Chetta A, Zanini A, Pisi G, Aiello M, Tzani P, Neri M, Olivieri D (2006) Reference values for the 6-min walk test in healthy subjects 20-50 years old. Respir Med 100:1573-1578 https://doi. org/10.1016/j.rmed.2006.01.001

Crouter SE, Schneider PL, Karabulut M, Bassett DR Jr (2003) Validity of 10 electronic pedometers for measuring steps, distance, and energy cost. Med Sci Sports Exerc 35:1455-1460. https://doi. org/10.1249/01.mss.0000078932.61440.a2

de Almeida Mendes M, da Silva ICM, Ramires VV, Reichert FF, Martins RC, Tomasi E (2018) Calibration of raw accelerometer data to measure physical activity: a systematic review. Gait Posture 61:98-110. https://doi.org/10.1016/j.gaitpost.2017.12.028

Dellal A, Keller D, Carling C, Chaouachi A, Wong del P, Chamari K (2010) Physiologic effects of directional changes in intermittent exercise in soccer players. J Strength Cond Res Natl Strength Cond Assoc 24:3219-3226. https://doi.org/10.1519/JSC.0b013 e3181b94a63

Dixon PC, Stebbins J, Theologis T, Zavatsky AB (2013) Spatio-temporal parameters and lower-limb kinematics of turning gait in typically developing children. Gait Posture 38:870-875. https:// doi.org/10.1016/j.gaitpost.2013.04.010

Doherty A, Jackson D, Hammerla N, Plotz T, Olivier P, Granat MH, White T, van Hees VT, Trenell MI, Owen CG, Preece SJ, Gillions R, Sheard S, Peakman T, Brage S, Wareham NJ (2017) Large scale population assessment of physical activity using wrist worn accelerometers: the UK Biobank Study. PLoS One 12:e0169649. https://doi.org/10.1371/journal.pone.0169649

Eime RM, Young JA, Harvey JT, Charity MJ, Payne WR (2013) A systematic review of the psychological and social benefits of participation in sport for children and adolescents: informing development of a. conceptual model of health through sport. Int J Behav Nutr Phys Act 10:98. https://doi.org/10.1186/1479-5868-10-98

Eisenmann JC, Strath SJ, Shadrick D, Rigsby P, Hirsch N, Jacobson L (2004) Validity of uniaxial accelerometry during activities of daily living in children. Eur J Appl Physiol 91:259-263. https:// doi.org/10.1007/s00421-003-0983-3

Esliger DW, Probert A, Connor Gorber S, Bryan S, Laviolette M, Tremblay MS (2007) Validity of the Actical accelerometer stepcount function. Med Sci Sports Exerc 39:1200-1204. https://doi. org/10.1249/mss.0b013e3804ec4e9
Fjørtoft I, Kristoffersen B, Sageie J (2009) Children in schoolyards: tracking movement patterns and physical activity in schoolyards using global positioning system and heart rate monitoring. Landsc Urban Plan 93:210-217

Fortune E, Lugade V, Morrow M, Kaufman K (2014) Validity of using tri-axial accelerometers to measure human movement-part II: step counts at a wide range of gait velocities. Med Eng Phys 36:659-669. https://doi.org/10.1016/j.medengphy.2014.02.006

Freedson P, Pober D, Janz KF (2005) Calibration of accelerometer output for children. Med Sci Sports Exerc 37:S523-S530

Freedson P, Bowles HR, Troiano R, Haskell W (2012) Assessment of physical activity using wearable monitors: recommendations for monitor calibration and use in the field. Med Sci Sports Exerc 44:S1-S4 https://doi.org/10.1249/MSS.0b013e3182399b7e

Geiger R, Strasak A, Treml B, Gasser K, Kleinsasser A, Fischer V, Geiger H, Loeckinger A, Stein JI (2007) Six-minute walk test in children and adolescents. J Pediatr 150:395-399. https://doi. org/10.1016/j.jpeds.2006.12.052 (399.e391-392)

Geldhof E, Cardon G, De Bourdeaudhuij I, Danneels L, Coorevits P, Vanderstraeten G, De Clercq D (2006) Static and dynamic standing balance: test-retest reliability and reference values in 9 to 10 year old children. Eur J Pediatr 165:779-786. https://doi. org/10.1007/s00431-006-0173-5

Glaister BC, Bernatz GC, Klute GK, Orendurff MS (2007) Video task analysis of turning during activities of daily living. Gait Posture 25:289-294. https://doi.org/10.1016/j.gaitpost.2006.04.003

Gleiss AC, Wilson RP, Shepard ELC (2011) Making overall dynamic body acceleration work: on the theory of acceleration as a proxy for energy expenditure. Methods Ecol Evol 2:23-33. https://doi. org/10.1111/j.2041-210X.2010.00057.x

Hader K, Mendez-Villanueva A, Palazzi D, Ahmaidi S, Buchheit M (2016) Metabolic power requirement of change of direction speed in young soccer players: not all is what it seems. PLoS One 11:e0149839. https://doi.org/10.1371/journal.pone.0149839

Halsey LG, Green JA, Wilson RP, Frappell PB (2009) Accelerometry to estimate energy expenditure during activity: best practice with data loggers. Physiol Biochem Zool 82:396-404. https:// doi.org/10.1086/589815

Halsey LG, Shepard EL, Wilson RP Part A (2011) Assessing the development and application of the accelerometry technique for estimating energy expenditure. Comp Biochem Physiol Mol Integr Physiol 158:305-314. https://doi.org/10.1016/j.cbpa.2010.09.002

Hamill J, Bates BT, Knutzen KM, Sawhill JA (1983) Variations in ground reaction force parameters at different running speeds. Hum Mov Sci 2:47-56. https://doi.org/10.1016/01679457(83)90005-2

Hase K, Stein RB (1999) Turning strategies during human walking. J Neurophysiol 81:2914-2922

Hatamoto Y, Yamada Y, Fujii T, Higaki Y, Kiyonaga A, Tanaka H (2013) A novel method for calculating the energy cost of turning during running. Open Access J Sports Med 4:117-122. https:// doi.org/10.2147/OAJSM.S39206

Hatamoto Y, Yamada Y, Sagayama H, Higaki Y, Kiyonaga A, Tanaka $H$ (2014) The relationship between running velocity and the energy cost of turning during running. PLoS One 9:e81850 https ://doi.org/10.1371/journal.pone.0081850

Havens KL, Sigward SM (2015) Whole body mechanics differ among running and cutting maneuvers in skilled athletes. Gait Posture 42:240-245. https://doi.org/10.1016/j.gaitpost.2014.07.022

Houston EL, Baker JS, Buchan DS, Stratton G, Fairclough SJ, Foweather L, Gobbi R, Graves LE, Hopkins N, Boddy LM (2013) Cardiorespiratory fitness predicts clustered cardiometabolic risk in 10-11.9-year-olds. Eur J Pediatr 172:913-918. https ://doi.org/10.1007/s00431-013-1973-Z 
Huxham F, Gong J, Baker R, Morris M, Iansek R (2006) Defining spatial parameters for non-linear walking. Gait Posture 23:159-163. https://doi.org/10.1016/j.gaitpost.2005.01.001

Hytönen M, Pyykkö I, Aalto H, Starck J (1993) Postural control and age. Acta Otolaryngol 113:119-122. https://doi. org/10.3109/00016489309135778

Janssen I, Leblanc AG (2010) Systematic review of the health benefits of physical activity and fitness in school-aged children and youth. Int J Behav Nutr Phys Act 7:40. https://doi. org/10.1186/1479-5868-7-40

Jones AM, Doust JH (1996) A 1\% treadmill grade most accurately reflects the energetic cost of outdoor running. J Sports Sci 14:321-327. https://doi.org/10.1080/02640419608727717

Justine M, Manaf H, Sulaiman A, Razi S, Alias HA (2014) Sharp turning and corner turning: comparison of energy expenditure, gait parameters, and level of fatigue among communitydwelling elderly. BioMed Res Int 2014:640321. https://doi. org/10.1155/2014/640321

Kenis-Coskun O, Giray E, Eren B, Ozkok O, Karadag-Saygi E (2016) Evaluation of postural stability in children with hemiplegic cerebral palsy. J Phys Ther Sci 28:1398-1402. https://doi. org/10.1589/jpts.28.1398

Le Masurier GC, Tudor-Locke C (2003) Comparison of pedometer and accelerometer accuracy under controlled conditions. Med Sci Sports Exerc 35:867-871. https://doi.org/10.1249/01.mss.00000 64996.63632 .10

Lee IM, Shiroma EJ (2014) Using accelerometers to measure physical activity in large-scale epidemiological studies: issues and challenges. Br J Sports Med 48:197-201. https://doi.org/10.1136/ bjsports-2013-093154

Leung W, Siebert EA, Yun J (2017) Measuring physical activity with accelerometers for individuals with intellectual disability: a systematic review. Res Dev Disabil 67:60-70. https://doi. org/10.1016/j.ridd.2017.06.001

Levine JA (2005) Measurement of energy expenditure. Public Health Nutr 8:1123-1132

Liao HF, Jeng SF, Lai JS, Cheng CK, Hu MH (1997) The relation between standing balance and walking function in children with spastic diplegic cerebral palsy. Dev Med Child Neurol 39:106-112

Lipkin DP, Scriven AJ, Crake T, Poole-Wilson PA (1986) Six minute walking test for assessing exercise capacity in chronic heart failure. Br Med J (Clin Res ed) 292:653-655

Mansfield A, Lyons GM (2003) The use of accelerometry to detect heel contact events for use as a sensor in FES assisted walking. Med Eng Phys 25:879-885

McGregor SJ, Busa MA, Yaggie JA, Bollt EM (2009) High resolution MEMS accelerometers to estimate $\mathrm{VO}(2)$ and compare running mechanics between highly trained inter-collegiate and untrained runners. PLoS One 4:e7355. https://doi.org/10.1371/ journal.pone.0007355

McNarry MA, Wilson RP, Holton MD, Griffiths IW, Mackintosh KA (2017) Investigating the relationship between energy expenditure, walking speed and angle of turning in humans. PLoS One 12:e0182333 https://doi.org/10.1371/journal.pone.0182333

Minetti AE (2001) Invariant aspects of human locomotion in different gravitational environments. Acta Astronaut 49:191-198

Minetti AE, Cazzola D, Seminati E, Giacometti M, Roi GS (2011) Skyscraper running: physiological and biomechanical profile of a novel sport activity. Scand J Med Sci Sports 21:293-301. https ://doi.org/10.1111/j.1600-0838.2009.01043.x

Mirwald RL, Baxter-Jones AD, Bailey DA, Beunen GP (2002) An assessment of maturity from anthropometric measurements. Med Sci Sports Exerc 34:689-694

Nieman P (2002) Psychosocial aspects of physical activity. Paediatr Child Health 7:309-312
O'Brien TD, Reeves ND, Baltzopoulos V, Jones DA, Maganaris CN (2009) Moment arms of the knee extensor mechanism in children and adults. J Anat 215:198-205. https://doi.org/10.111 $1 / \mathrm{j} .1469-7580.2009 .01088 . x$

Orendurff MS, Segal AD, Berge JS, Flick KC, Spanier D, Klute GK (2006) The kinematics and kinetics of turning: limb asymmetries associated with walking a circular path. Gait Posture 23:106111. https://doi.org/10.1016/j.gaitpost.2004.12.008

Patla AE, Prentice SD, Robinson C, Neufeld J (1991) Visual control of locomotion: strategies for changing direction and for going over obstacles. J Exp Psychol Hum Percept Perform 17:603-634

Patla AE, Adkin A, Ballard T (1999) Online steering: coordination and control of body center of mass, head and body reorientation. Exp Brain Res 129:629-634

Qasem L, Cardew A, Wilson A, Griffiths I, Halsey LG, Shepard EL, Gleiss AC, Wilson R (2012) Tri-axial dynamic acceleration as a proxy for animal energy expenditure; should we be summing values or calculating the vector? PLoS One 7:e31187. https://doi. org/10.1371/journal.pone.0031187

Reilly JJ, Jackson DM, Montgomery C, Kelly LA, Slater C, Grant S, Paton JY (2004) Total energy expenditure and physical activity in young Scottish children: mixed longitudinal study. Lancet (Lond Engl) 363:211-212

Rowlands AV (2007) Accelerometer assessment of physical activity in children: an update. Pediatr Exerc Sci 19:252-266

Rueterbories J, Spaich EG, Larsen B, Andersen OK (2010) Methods for gait event detection and analysis in ambulatory systems. Med Eng Phys 32:545-552. https://doi.org/10.1016/j.meden gphy.2010.03.007

Salarian A, Russmann H, Vingerhoets FJ, Dehollain C, Blanc Y, Burkhard PR, Aminian K (2004) Gait assessment in Parkinson's disease: toward an ambulatory system for long-term monitoring. IEEE Trans Bio-med Eng 51:1434-1443. https://doi. org/10.1109/tbme.2004.827933

Sankoh AJ, Huque MF, Dubey SD (1997) Some comments on frequently used multiple endpoint adjustment methods in clinical trials. Stat Med 16:2529-2542

Schärli AM, Keller M, Lorenzetti S, Murer K, van de Langenberg R (2013) Balancing on a slackline: 8-year-olds vs. Adults. Front Psychol 4:208. https://doi.org/10.3389/fpsyg.2013.00208

Schot P, Dart J, Schuh M (1995) Biomechanical analysis of two change-of-direction maneuvers while running. J Orthop Sports Phys Ther 22:254-258. https://doi.org/10.2519/jospt .1995.22.6.254

Shepard EL, Wilson RP, Liebsch N, Quintana F, Laich AG, Lucke K (2008) Flexible paddle sheds new light on speed: a novel method for the remote measurement of swim speed in aquatic animals. Endanger Species Res 4:157-164

Sleap M, Warburton P (1996) Physical activity levels of 5-11-yearold children in England: cumulative evidence from three direct observation studies. Int J Sports Med 17:248-253. https://doi. org/10.1055/s-2007-972841

Sothern MS, Loftin M, Suskind RM, Udall JN, Blecker U (1999) The health benefits of physical activity in children and adolescents: implications for chronic disease prevention. Eur J Pediatr 158:271-274

Sparrow WA (2000) Energetics of human activity, 1st edn. Human Kinetics, USA, p 100

Stone MR, Rowlands AV, Middlebrooke AR, Jawis MN, Eston RG (2009) The pattern of physical activity in relation to health outcomes in boys. Int J Pediatr Obes 4:306-315. https://doi. org/10.3109/17477160902846179

Strath SJ, Kaminsky LA, Ainsworth BE, Ekelund U, Freedson PS, Gary RA, Richardson CR, Smith DT, Swartz AM (2013) Guide to the assessment of physical activity: clinical and research applications: a scientific statement from the American 
Heart Association. Circulation 128:2259-2279. https://doi. org/10.1161/01.cir.0000435708.67487.da

Tanner JM (1962) Growth at adolescence, with a general consideration of the effects of hereditary and environmental factors upon growth and maturation from birth to maturity, $2 \mathrm{~d}$ edn. Blackwell Scientific Publications, Oxford

Taylor MJ, Dabnichki P, Strike SC (2005) A three-dimensional biomechanical comparison between turning strategies during the stance phase of walking. Hum Mov Sci 24:558-573. https:// doi.org/10.1016/j.humov.2005.07.005

Townsend N, Wickramasinghe K, Williams J, Bhatnagar P, Rayner M (2015) Physical activity statistics 2015. Nuffield Department of Population Health, University of Oxford British Heart Foundation, London

Troosters T, Gosselink R, Decramer M (1999) Six minute walking distance in healthy elderly subjects. Eur Respir J 14:270-274

Trost SG, Loprinzi PD, Moore R, Pfeiffer KA (2011) Comparison of accelerometer cut points for predicting activity intensity in youth. Med Sci Sports Exerc 43:1360-1368. https://doi. org/10.1249/MSS.0b013e318206476e

Tukey JW (1977) Exploratory data analysis. Addison-Wesely, Boston

Tukey J, Ciminera J, Heyse J (1985) Testing the statistical certainty of a response to increasing doses of a drug. Biometrics 41:295-301

Van Remoortel H, Giavedoni S, Raste Y, Burtin C, Louvaris Z, Gimeno-Santos E, Langer D, Glendenning A, Hopkinson NS, Vogiatzis I, Peterson BT, Wilson F, Mann B, Rabinovich R, Puhan MA, Troosters T (2012) Validity of activity monitors in health and chronic disease: a systematic review. Int J Behav Nutr Phys Act 9:84. https://doi.org/10.1186/1479-5868-9-84

Veloso-Guedes CA, Rosalen ST, Thobias CM, Andreotti RM, Galhardo FDM, Oliveira da Silva AM, Araujo O, Boin IFSF (2011) Validation of 20-meter corridor for the 6-minute walk test in men on liver transplantation waiting list. Transplant Proc 43:1322-1324. https://doi.org/10.1016/j.transproceed.2011.03.057

Ward DS, Evenson KR, Vaughn A, Rodgers AB, Troiano RP (2005) Accelerometer use in physical activity: best practices and research recommendations. Med Sci Sports Exerc 37:S582-S588

Waters RL, Mulroy S (1999) The energy expenditure of normal and pathologic gait. Gait Posture 9:207-231
Weippert M, Stielow J, Kumar M, Kreuzfeld S, Rieger A, Stoll R (2013) Tri-axial high-resolution acceleration for oxygen uptake estimation: validation of a multi-sensor device and a novel analysis method. Appl Physiol Nutr Metab (Physiologie appliquee nutrition et metabolisme) 38:345-351. https://doi.org/10.1139/ apnm-2012-0228

Welk GJ, Corbin CB, Dale D (2000) Measurement issues in the assessment of physical activity in children. Res Q Exerc Sport 71:S59-S73

Welsman JR, Armstrong N (2000) Statistical techniques for interpreting body size-related exercise performance during growth. Pediatr Exerc Sci 12:112-127

Westerterp KR (2009) Assessment of physical activity: a critical appraisal. Eur J Appl Physiol 105:823-828. https://doi. org/10.1007/s00421-009-1000-2

WHO (2017) Physical activity. http://www.who.int/mediacentre/facts heets/fs385/en/. Accessed 22 July 2017

Williams HJ, Holton MD, Shepard ELC, Largey N, Norman B, Ryan PG, Duriez O, Scantlebury M, Quintana F, Magowan EA, Marks NJ, Alagaili AN, Bennett NC, Wilson RP (2017) Identification of animal movement patterns using tri-axial magnetometry. Mov Ecol 5:6. https://doi.org/10.1186/s40462-017-0097-x

Willis WT, Ganley KJ, Herman RM (2005) Fuel oxidation during human walking. Metab Clin Exp 54:793-799. https://doi. org/10.1016/j.metabol.2005.01.024

Wilson RP, Griffiths IW, Legg PA, Friswell MI, Bidder OR, Halsey LG, Lambertucci SA, Shepard EL (2013) Turn costs change the value of animal search paths. Ecol Lett 16:1145-1150. https:// doi.org/10.1111/ele.12149

Winter DA, Patla AE, Frank JS (1990) Assessment of balance control in humans. Med Progr Through Technol 16:31-51

Zadro I, Sepulcri L, Lazzer S, Fregolent R, Zamparo P (2011) A protocol of intermittent exercise (shuttle runs) to train young basketball players. J Strength Cond Res Natl Strength Cond Assoc 25:1767-1773. https://doi.org/10.1519/JSC.0b013e3181da85d1

Zarrugh MY, Todd FN, Ralston HJ (1974) Optimization of energy expenditure during level walking. Eur J Appl Physiol Occup Physiol. https://doi.org/10.1007/BF00430237 